\title{
Effect of Psychological Intervention of King's Interactive Standard on the Rehabilitation Process and Nursing Satisfaction of Patients with Severe Acute Pancreatitis in ICU
}

\author{
Huifang Wang \\ Henan Province Hospital of Traditional Chinese Medicine, Zhengzhou, Henan, 450002
}

Keywords: ICU severe acute pancreatitis; King interaction standard theory; psychological intervention; rehabilitation process

\begin{abstract}
Objective: To analyze the effect of psychological intervention on the rehabilitation process and nursing satisfaction of patients with severe acute pancreatitis (SAP) in ICU. Methods: 98 patients with SAP admitted to our hospital from January 2015 to February 2018 were enrolled in the observation group (49 cases) and the control group (49 cases). The control group underwent routine psychological intervention and the observation group performed King. Psychological intervention of interactive compliance theory, comparing rehabilitation status, acute physiology and chronic health status scores before and after intervention (APACHE II score), World Health Organization quality of life (QOL) score, Hamilton anxiety scale (HAMA) score and nursing satisfaction. Results: The abdominal pain time, spontaneous defecation time and average hospitalization time in the observation group were shorter than those in the control group $(\mathrm{P}<0.05)$. The APACHE II scores of the two groups were smaller than those before the intervention, and the QOL scores were larger than before the intervention, and the improvement degree of the observation group was greater than that before the intervention. The control group $(\mathrm{P}<0.05)$; the HAMA score of the observation group was lower than that of the control group $(\mathrm{P}<0.05)$; the nursing satisfaction of the observation group was $93.88 \%$ higher than that of the control group (71.43\%) $(\mathrm{P}<0.05)$. Conclusion: The psychological intervention of King's interactive standard theory can alleviate the condition of SAP patients, improve their psychological state, promote patient rehabilitation, and improve nursing satisfaction and quality of life.
\end{abstract}

\section{Introduction}

Severe acute pancreatitis (SAP) is a special type of acute pancreatitis, accounting for $10 \%$ to $20 \%$ of the entire acute pancreatitis. It has the characteristics of serious illness, complications and high mortality [1]. With the improvement of SAP internal surgical treatment technology, the cure rate has increased, but the overall mortality rate is still around $17 \%$. Previous studies have indicated that nursing intervention in patients with SAP can promote the outcome of the disease [2-3]. King's interactive compliance theory was proposed by American nursing theory expert King, expounding the four themes of interpersonal relationship, perception, health and social system, promoting mutual communication between nurses and patients, jointly developing nursing goals, and participating in the goal realization process. At present, there are few reports on the psychological intervention of King's interactive compliance theory, and this study is the first to apply it to ICU patients with severe acute pancreatitis, to explore its impact on the patient's rehabilitation process and nursing satisfaction, as reported below.

\section{Materials and methods}

General Information 98 patients with SAP admitted to our hospital from January 2015 to February 2018 were enrolled in the observation group (49 cases) and the control group (49 cases). Among them, there were 27 males and 22 females, aged 23-65 years old, with an average of (37.78 \pm 7.39$)$ years old, 8 cases of high-fat diet, 5 cases of alcohol abuse, 19 cases of biliary infection, and 17 cases of stone disease. In the control group, 24 males and 25 females, aged 22-67 
years, mean (36.16 \pm 7.08$)$ years old, 10 cases of high-fat diet, 4 cases of alcohol abuse, 15 cases of biliary infection, stone disease 20 cases. The differences in gender, age, and cause of disease between the two groups were balanced $(\mathrm{P}>0.05)$. This study meets the relevant requirements of the Helsinki Declaration of the World Medical Association.

Inclusion criteria and exclusion criteria (1) Inclusion criteria: primary school and above, with normal communication skills; meet SAP diagnostic criteria [4]; Acute physiology and chronic health evaluation (APACHE II score) $\geq 8$ points; signed informed consent; no malignant tumors. (2) Exclusion criteria: pancreatic or ampullary tumor, pancreatic hemorrhage and necrosis; important organs with severe dysfunction; accompanied by mental illness; pregnant patients.

Methods Both groups were admitted to the hospital for physical examination, laboratory examinations, and closely monitored vital signs, nutritional support, oxygen inhalation, etc., and given symptomatic treatment according to doctor's advice. (1) Control group: carry out routine psychological interventions, such as answering patient questions and encouraging comfort patients. (2) Observation group: The psychological intervention of King's interactive compliance theory is as follows. (1) Assessment: King theory believes that individual knowledge, skills, background, ability, and values are different, and there are differences in the description of reality. The patient's physical, physiological, and spiritual factors should be evaluated to grasp the patient's psychological state and causes; (2) Diagnosis: King theory points out that diagnosis is the result of sharing evaluations between nurses and patients. The content must be unanimously recognized by both parties. For different opinions, deep understanding should be established on the basis of respect and understanding, and patients' needs should be met as much as possible to establish mutual care goals; (3) Plan: King theory points out that both nurses and patients have the right to participate in the care plan development process. Nursing staff should pay attention to patient opinions and suggestions, communicate with patients in a timely manner, and encourage family members to participate in collaborative research on nursing plans; 4) Execution: 1 Establishment of nurse-patient relationship: After the patient enters the ICU, the nursing staff should maintain an active service attitude, receive the patient at the first time, serve frankly, stabilize the patient's emotions, and increase mutual trust; 2 environmental care: easy environment Make patients feel irritated, caregivers should not be too big Speaking and laughing, lowering the sound of the monitoring equipment, keeping the indoor light soft, and disinfecting the room regularly; 3 interaction between nurses and patients: whispering the patient's condition and discomfort, listening carefully to the patient, giving encouragement, comfort, praise, etc. To the discomfort, if the patient is inconvenient to communicate with words, they can communicate through eyes and gestures, pay attention to observe the patient's mouth shape, expression, movement, etc., understand their needs, provide them with tacit nursing services; 4 family support: in the patient's condition When allowed, family members may be allowed to visit patients at their discretion. Family members are more relieved, encourage patients, avoid talking about hospitalization expenses, etc. 5 Observe changes in mental state: strengthen daily inspections, pay attention to observe changes in mental and psychological state of patients, according to psychological state Changes in time to adjust the psychological care program.

Observation indicators (1) Abdominal pain time, spontaneous defecation time, average hospital stay days. (2) Before and after the intervention, the APACHE II scoring system and the World Health Organization Quality of Life (QOL) assessment form were used to evaluate the condition and quality of life of the two groups. (3) Anxiety status before and after intervention was assessed by Hamilton Anxiety Scale (HAMA). (4) Nursing satisfaction is divided into very satisfied, satisfied, and dissatisfied. The sum of the first two is satisfaction. Very satisfied: the score of the self-made $100 \%$ nursing satisfaction questionnaire in our hospital is $>80$ points; satisfaction: the nursing satisfaction questionnaire is 50 to 80 points; the dissatisfaction: the nursing satisfaction questionnaire is $<50$ points.

Statistical methods SPSS20.0 statistical software was used to process the data. The measurement data was expressed by $( \pm \mathrm{s}), \mathrm{t}$ test, and the count data was expressed by $\mathrm{n}(\%)$ and $\chi 2$ test. $\mathrm{P}<0.05$ was considered statistically significant. 


\section{Results}

Rehabilitation the abdominal pain time, spontaneous defecation time, and average hospital stay in the observation group were shorter than those in the control group $(\mathrm{P}<0.05)$. See Table 1.

Table 1 Comparison of abdominal pain time, spontaneous defecation time, and average length of hospital stay $(\bar{x} \pm \mathrm{s}, \mathrm{d})$

\begin{tabular}{ccccc}
\hline Gr. & Case & $\begin{array}{c}\text { Abdominal pain } \\
\text { time }\end{array}$ & $\begin{array}{c}\text { Autonomous } \\
\text { defecation time }\end{array}$ & $\begin{array}{c}\text { Average hospital } \\
\text { stay }\end{array}$ \\
\hline $\begin{array}{c}\text { Observation } \\
\text { group }\end{array}$ & 49 & $2.96 \pm 1.12$ & $3.92 \pm 1.41$ & $17.88 \pm 5.25$ \\
Control & 49 & $5.63 \pm 0.95$ & $5.16 \pm 1.22$ & $26.39 \pm 7.14$ \\
group & & & & \\
$t$ & & 12.726 & 4.655 & 6.722 \\
$P$ & & 0.000 & 0.000 & 0.000 \\
\hline
\end{tabular}

Disease and quality of life There was no significant difference in APACHE II and QOL scores between the two groups before intervention $(\mathrm{P}>0.05)$. After the intervention, the APACHE II scores of the two groups were smaller than before the intervention, and the QOL scores were larger than before the intervention, and the improvement degree of the observation group after intervention. Greater than the control group $(\mathrm{P}<0.05)$. See Table 2 .

Table 2 Comparison of APACHE II and QOL scores between the two groups before and after intervention ( $\bar{x} \pm \mathrm{s}$, points)

\begin{tabular}{|c|c|c|c|c|c|c|c|c|c|}
\hline \multirow[b]{2}{*}{ Gr. } & \multirow[b]{2}{*}{ Case } & \multicolumn{2}{|c|}{ APACHE IIScore } & \multirow[b]{2}{*}{$t$} & \multirow[b]{2}{*}{$P$} & \multicolumn{2}{|c|}{ QOL score } & \multirow[b]{2}{*}{$t$} & \multirow[b]{2}{*}{$P$} \\
\hline & & $\begin{array}{c}\text { Before } \\
\text { intervention }\end{array}$ & $\begin{array}{c}\text { After } \\
\text { intervention }\end{array}$ & & & $\begin{array}{c}\text { Before } \\
\text { intervention }\end{array}$ & $\begin{array}{c}\text { After } \\
\text { intervention }\end{array}$ & & \\
\hline $\begin{array}{l}\text { Observati } \\
\text { on group }\end{array}$ & 49 & $46.17 \pm 5.22$ & $20.14 \pm 8.66$ & 18.020 & 0.000 & $35.19 \pm 7.81$ & $71.34 \pm 10.01$ & 19.931 & 0.000 \\
\hline $\begin{array}{l}\text { Control } \\
\text { group }\end{array}$ & 49 & $47.25 \pm 4.85$ & $27.33 \pm 6.24$ & 17.644 & 0.000 & $36.33 \pm 9.42$ & $63.49 \pm 11.13$ & 13.039 & 0.000 \\
\hline$t$ & & 1.061 & 4.715 & & & 0.652 & 3.671 & & \\
\hline$P$ & & 0.291 & 0.000 & & & 0.516 & 0.000 & & \\
\hline
\end{tabular}

Anxiety The difference between the two groups was not significant $(\mathrm{P}>0.05)$. The HAMA score of the observation group was lower than that before the intervention, and the HAMA score of the observation group was lower than that of the control group $(\mathrm{P}<0.05)$. See Table 3.

Table 3 Comparison of anxiety before and after intervention in both groups $(\bar{x} \pm \mathrm{s}, \mathrm{min})$

\begin{tabular}{cccccc}
\hline Gr. & Case & $\begin{array}{c}\text { Before } \\
\text { intervention }\end{array}$ & $\begin{array}{c}\text { After } \\
\text { intervention }\end{array}$ & $t$ & $P$ \\
\hline $\begin{array}{c}\text { Observation } \\
\text { group }\end{array}$ & 49 & $65.14 \pm 9.68$ & $23.71 \pm 6.28$ & 25.134 & 0.000 \\
Control & 49 & $64.84 \pm 10.27$ & $35.08 \pm 5.66$ & 17.765 & 0.000 \\
group & & & & & \\
$t$ & & 0.149 & 9.414 & & \\
$P$ & & 0.882 & 0.000 & & \\
\hline
\end{tabular}

Nursing satisfaction The nursing satisfaction of the observation group was $93.88 \%$ higher than that of the control group (71.43\%) $(\mathrm{P}<0.05)$. See Table 4. 
Table 4 Comparison of nursing satisfaction between the two groups $n(\%)$

\begin{tabular}{cccccc}
\hline Gr. & Case & Very satisfied & satisfaction & $\begin{array}{c}\text { Not } \\
\text { satisfied }\end{array}$ & Satisfaction \\
\hline $\begin{array}{c}\text { Observation } \\
\text { group }\end{array}$ & 49 & $29(59.18)$ & $17(34.69)$ & $3(6.12)$ & $46(93.88)$ \\
Control & 49 & $20(40.82)$ & 15(30.61) & $14(28.57)$ & $35(71.43)$ \\
group & & & & & \\
$\chi^{2}$ & & & & & 8.612 \\
$P$ & & & & & 0.003 \\
\hline
\end{tabular}

\section{Discussion}

SAP has many treatment strategies, including supplementation of water and electrolytes, gastrointestinal decompression, fasting, correction of acid-base balance, pain relief, inhibition of gastric juice and pancreatic fluid secretion, maintenance of organ function, prevention and control of infection, surgical treatment, etc., although medical technology High treatment has improved the success rate, but previous studies have shown that about $10 \%$ of patients still die [5-6]. As an auxiliary intervention for promoting disease rehabilitation, nursing intervention is of great significance to improve the therapeutic effect, promote the rehabilitation of patients and improve the prognosis of patients.

King's interactive compliance theory focuses on the interaction between nurses and patients, requiring caregivers and patients to participate in the whole process of nursing activities, including emotional assessment, diagnosis, planning, implementation, etc., paying attention to the nursing process and results, to ensure that each project has good quality, Thereby improving the quality of care. Gao Jie et al [7] research shows that King's interactive standards can improve the communication ability of intern nurses; Zhu Yuhong et al [8] pointed out that psychological nursing intervention based on King's standard theory can improve the compliance of patients with benign prostatic hyperplasia and shorten the length of hospital stay. This study was the first psychological intervention in the application of King's interactive compliance theory to SAP patients. The results showed that the abdominal pain time, spontaneous defecation time, and average hospital stay were shorter in the observation group than in the control group. The APACHE II and HAMA scores after intervention were lower than those in the control group $(\mathrm{P}<0.05)$. It is suggested that the psychological intervention of King's interactive compliance theory can alleviate the condition of SAP patients, improve their psychological state and promote the recovery of patients. King's interactive compliance theory regards nursing staff and patients as interpersonal systems between two individuals, exchanges information, participates in psychological state assessment, diagnosis, goal setting, and development and implementation of nursing measures, so as to timely understand the patient's inner needs and pressure. Accurately grasp the timing of psychological care intervention, carry out psychological nursing for SAP's inner emotional changes, enable patients to correctly understand their own situation and situation, remind patients to accept themselves, help guide their self-psychological adjustment, positively influence and change patients, so that nurses and patients Role functions are implemented, and through mutual interaction and interaction, the common goal of care is finally achieved. In addition, based on the above studies, this study found that the nursing satisfaction and QOL scores of the observation group were higher than those of the control group $(\mathrm{P}<0.05)$, suggesting that the psychological intervention of King's interactive compliance theory can improve the satisfaction and quality of life of SAP patients.

In summary, the psychological intervention of King's interactive compliance theory can alleviate the condition of SAP patients, improve their psychological state, promote patient rehabilitation, improve nursing satisfaction and quality of life. 


\section{References}

[1] Pan Li. Effect of enteral nutrition on clinical treatment of severe acute pancreatitis and nursing methods [J]. Hebei Medical Journal, 2016, 22(12):2111-2112.

[2] Zhang Huafang. Effect of comprehensive nursing on APACHE II score and intestinal dysfunction in patients with severe acute pancreatitis[J].Journal of Clinical Medicine in Practice,2015,19(20):128-129.

[3] Shan Guanghui, Jin Na, Dong Qing, et al. Effects of psychological nursing on mental state and quality of life in critically ill patients with ICU [J]. International Journal of Psychiatry, 2017, 44(5): 940-943.

[4] Pancreatic Surgery Group of the Chinese Medical Association Surgery Branch. Guidelines for the diagnosis and treatment of acute pancreatitis (2014 edition) [J]. Journal of Clinical Hepatology, 2015, 14 (1): 1-5.

[5] Xie Donglian. Clinical observation of individualized health education in nursing intervention of acute pancreatitis[J].Modern Digestive \& Interventional Therapy,2016,21(4):648-650.

[6] Liu Guilan, Xu Sheling, Zhang Lanhua, et al. Analysis of common complications of severe acute pancreatitis and the effect of preventive nursing measures [J]. Modern Digestive and Interventional Diagnosis and Treatment, 2015, 20 (03): 299-300.

[7] Gao Jie, Chen Ying, Liu Li. The application of King's interactive compliance theory in the communication ability of intern students[J]. Chinese Journal of Modern Nursing, 2015, 21(11): 1251-1254.

[8] Zhu Yuhong, Wu Lifen. Application of psychological nursing intervention based on King's standard theory in postoperative patients with benign prostatic hyperplasia[J].Chinese Journal of Endemiology and Prevention,2017,32(09):1044-1045. 